\title{
Comparison of Safety between Different Kinds of Heparins in Patients Receiving Intra-Aortic Balloon Counterpulsation
}

\author{
Xiaonan Guan ${ }^{1}$ Mulei Chen ${ }^{1}$ Yanbing $\mathrm{Li}^{1} \quad$ Jianjun Zhang ${ }^{1} \quad \mathrm{Li} \mathrm{Xu}^{1}$ Hao Sun ${ }^{1}$ Dapeng Zhang ${ }^{1}$ \\ Lefeng Wang ${ }^{1}$ Xinchun Yang ${ }^{1}$
}

${ }^{1}$ Center of Cardiology, Beijing Chaoyang Hospital, Beijing, People's

Address for correspondence Mulei Chen, MS, Center of Cardiology, Republic of China Beijing Chaoyang Hospital, 8 Gongren Tiyuchang Nanlu, Beijing

Thorac Cardiovasc Surg 2021;69:511-517. 100020, People’s Republic of China (e-mail: cml68cy@yeah.net).

\begin{abstract}
\section{Keywords}

- low-molecular-weight heparin

- unfractionated heparin

- acute myocardial infarction

- intra-aortic balloon counterpulsation

Background The present study aimed to compare the effectiveness and safety of low molecular-weight-heparin (LMWH) and unfractionated heparin (UFH) in acute myocardial infarction (AMI) patients receiving intra-aortic balloon counterpulsation (IABP). Materials and Methods We retrospectively analyzed a total of 344 patients receiving IABP for cardiogenic shock, severe heart failure, ventricular septal rupture, or mitral valve prolapse due to AMI. A total of 161 patients received UFH (a bolus injection 70 $\mathrm{U} / \mathrm{kg}$ immediately after IABP, followed by infusion at a rate of $15 \mathrm{U} / \mathrm{kg} /$ hour and titration to for 50 to 70 seconds of activated partial thromboplastin time. A total of 183 patients received LMWH (subcutaneous injection of $1.0 \mathrm{mg} / \mathrm{kg}$ every 12 hours for 5 to 7 days and $1.0 \mathrm{mg} / \mathrm{kg}$ every 24 hours thereafter). Events of ischemia, arterial thrombosis or embolism, and bleeding during IABP were evaluated. Major bleeding was defined as a hemoglobin decrease by $>50 \mathrm{~g} / \mathrm{L}$ (vs. prior to IABP) or bleeding that caused hemodynamic shock or life-threatening or requiring blood transfusion.

Results Subjects receiving UFH and LMWH did not differ in baseline characteristics. Ischemia was noted in five $(3.1 \%)$ and two $(1.1 \%)$ subjects in UFH and LMWH groups, respectively. Arterial thromboembolism occurred in three (1.9\%) subjects in the UFH group, but not in the LMWH group. Logistic regression analysis failed to reveal an association between ischemia or bleeding with heparin type. Major bleeding occurred in $16(9.9 \%)$ and six (3.3\%) patients in the UFH and LWMH groups, respectively $(p=0.014)$. Regression analysis indicated that LMWH is associated with less major bleeding.

Conclusion $\mathrm{LMWH}$ could reduce the risk of major bleeding in patients receiving IABP. Whether LMWH could reduce arterial thromboembolism needs further investigation.
\end{abstract}

received

March 2, 2020 accepted after revision July 24, 2020 published online September 30, 2020
DOI https://doi.org/ 10.1055/s-0040-1716390. ISSN 0171-6425. (c) 2020. The Author(s).

This is an open access article published by Thieme under the terms of the Creative Commons Attribution-NonDerivative-NonCommercial-License, permitting copying and reproduction so long as the original work is given appropriate credit. Contents may not be used for commercial purposes, or adapted, remixed, transformed or built upon. (https://creativecommons.org/ licenses/by-nc-nd/4.0/)

Georg Thieme Verlag KG, Rüdigerstraße 14, 70469 Stuttgart, Germany 


\section{Introduction}

Cardiogenic shock develops in up to $3 \%$ of patients with non-ST elevation-acute coronary syndrome (NSTE-ACS), and in up to 6 to $10 \%$ of patients with ST segment elevation myocardial infarction (STEMI) during hospitalization, representing a common cause of in-hospital mortality in such patients. ${ }^{1,2}$ Intraaortic balloon counterpulsation (IABP) is a device commonly used to assist the function of left ventricles in patients who develop cardiogenic shock after acute myocardial infarction (AMI). ${ }^{3}$ To minimize the likelihood of catheter-related thrombosis and embolism, anticoagulant(s) must be used-typically with unfractionated heparin (UFH)-at an infusion rate that maintains the activated partial thromboplastin time (aPTT) within 50 to 70 seconds. $^{4}$ Low-molecular-weight heparin (LMWH, $\sim 4.5 \mathrm{kD}$ ) inhibits the Xa/Ila activity at a ratio of 1.5 to $4.0: 1.0$, as opposed to $1.0: 1.0$ for UFH. As a consequence, LMWH has lower antithrombotic ability and less impact on aPTT. Furthermore, LMWH has more desirable pharmacokinetic properties (almost complete absorption upon subcutaneous injection and less protein binding), and thereby has a more predictable dose-effect relationship. ${ }^{5}$ A meta-analysis of clinical trials, with a total of $>49,000$ ACS patients treated with LMWH versus UFH, revealed a lower rate of major adverse events (a composite outcome that included death, MI, and major bleeding within 30 days) with enoxaparin in patients with STEMI (odds ratio [OR]: $0.84, p=0.015$ ). ${ }^{6}$ The ATOLL trial also demonstrated the reduced death and recurrence of MI with LMWH (relative to UFH). ${ }^{7}$

In the last decade, LMWH has been increasingly used for hemodialysis and percutaneous coronary intervention (PCI). Study results have indicated that LMWH does not increase the risk of thrombosis and bleeding in patients receiving PCI. $^{8}$ In addition, LMWH has been proven to be safe for patients receiving hemodialysis. ${ }^{9,10}$ However, no clinical trial or retrospective study has convincingly shown that LMWH is safe for patients receiving IABP. The present retrospective analysis compared the effectiveness and safety of LMWH versus UFH in patients receiving IABP.

\section{Materials and Methods}

\section{Patients}

The present study was conducted in accordance with the Declaration of Helsinki and was approved by the ethics committee of our hospital.

The initial review of medical records identified 420 patients receiving IABP for cardiogenic shock, serious heart failure, or unstable hemodynamics due to AMI from January 2008 to December 2015 (-Fig. 1). A total of 35 cases were excluded from the data analysis due to coronary artery bypass grafting during IABP. Furthermore, 41 patients receiving heparin plus bivalirudin, glycoprotein IIb/IIIa antagonists, or fondaparinux were also excluded. The final data analysis included 344 cases. The IABP ( $8 \mathrm{~F}$ sheath tube, 34 or 40 cc; Datascope, CS100 type; Fairfield, New Jersey, United States) was implemented through the femoral artery for all cases. A total of 161 patients, who were admitted from January 2008 to December 2012, received UFH at a bolus injection $70 \mathrm{U} / \mathrm{kg}$ immediately after IABP, followed by infusion at a rate of $15 \mathrm{U} / \mathrm{kg} /$ hour and titration for 50 to 70 seconds of aPTT. ${ }^{11}$ A total of 183 patients, who were admitted from January 2013 to December 2015, received LMWH ( $n=82$ for enoxaparin; $n=101$ for nadroparin) using the following scheme according to European Society of Cardiology guidelines for AMI and ExTRACT-TIMI 25 trial: subcutaneous injection of $1.0 \mathrm{mg} / \mathrm{kg}$ every 12 hours for 5 to 7 days, and $1.0 \mathrm{mg} / \mathrm{kg}$ every 24 hours thereafter. LMWH was adjusted to $0.75 \mathrm{mg} / \mathrm{kg}$ for elderly subjects ( $\geq 75$ years old), and to once every 24 hours for subjects with an estimated glomerular filtration rate (eGFR) of $\leq 30 \mathrm{~mL} / \mathrm{min}$.

\section{Definition}

The diagnosis of AMI was established based on electrocardiogram (ECG) changes and/or cardiac enzyme profiles using

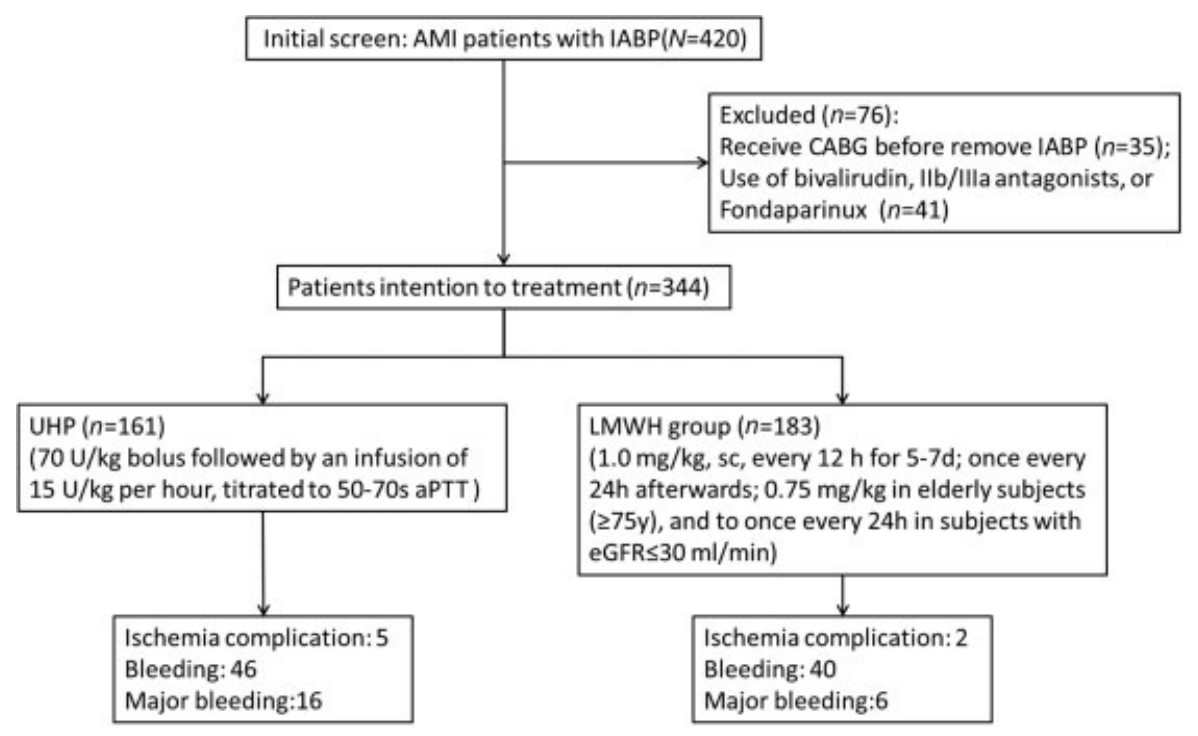

Fig. 1 Flow chart of the present study. 
the fourth universal definition of myocardial infarction. ${ }^{12}$ Cardiogenic shock was established using the following criteria: signs of organ hypoperfusion (cool peripheries and oliguria) plus one of the following: systolic blood pressure $\leq 90 \mathrm{~mm} \mathrm{Hg}$ for at least 30 minutes, hypotension requiring inotropic/vasopressor therapy at a heart rate $\geq 60$ /minute, or cardiac index $\leq 2.21 /$ minute $/ \mathrm{m}^{2}$ on invasive monitoring. ${ }^{13}$ Hypertension was defined as systolic blood pressure $\geq 140 \mathrm{mmHg}$ and/or diastolic blood pressure $\geq 90 \mathrm{~mm}$ Hg. ${ }^{14}$ Diabetes was established by fasting plasma glucose $\geq 126 \mathrm{mg} / \mathrm{dL}$ or 2 -hour plasma glucose $\geq 200 \mathrm{mg} / \mathrm{dL}$. ${ }^{15}$ Dyslipidemia was established by one or more of the following conditions: total cholesterol $>200 \mathrm{mg} / \mathrm{dL}$, low-density lipoprotein cholesterol $>100 \mathrm{mg} / \mathrm{dL}$, high-density lipoprotein cholesterol $<40 \mathrm{mg} / \mathrm{dL}$, and triglycerides $>150 \mathrm{mg} / \mathrm{dL}^{16}$

\section{Measures of Primary Interest}

The measures of primary interest included ischemia complication (limb ischemia and mesenteric ischemia) and bleeding during IABP. For suspected cases, vascular ultrasonography was performed to verify the arterial thrombosis and embolism. Major bleeding was defined as a hemoglobin decrease by $>50 \mathrm{~g} / \mathrm{L}$ (vs. prior to IABP) or bleeding that caused hemodynamic shock, or life-threatening or requiring blood transfusion. The hemoglobin and platelet count were recorded every day.

\section{Statistical Analysis}

Continuous variables are presented as mean \pm standard deviation, and analyzed using Student's $t$-test. Categorical variables are presented in percentage, and analyzed using Chi-square test. Multivariate logistic regression was conducted to examine the association of outcome measures (e.g., major bleeding) with the following factors: age, gender, history of hypertension and diabetes, cardiogenic shock, IABP time (groups $\leq 72$ hours and $>72$ hours), CRUSADE score (groups $\leq 40$ and $>40$ ), and heparin type. The $p$-value $<0.05$ was considered statistically significant.

\section{Results}

\section{Baseline Characteristics of Patients}

As shown in - Table 1, there was no significant difference between the UFH group and LMWH group in terms of the baseline characteristics. Five of the 161 patients receiving UFH (3.1\%) developed ischemia complication. Mesenteric artery embolism was noted in two cases with abdominal pain as the first symptom and confirmed using the computed tomography angiography. Bilateral femoral artery thrombus was confirmed in one case. For the remaining two cases, the vascular ultrasonography did not reveal an arterial thromboembolism. Two of the 183 subjects who received LMWH (1.1\%) developed ischemia. However, the vascular ultrasonography failed to identify the arterial thromboembolism in both cases.

\section{Potential Factors Associated with Ischemia}

The multivariate logistic regression analysis failed to reveal an association between ischemia and heparin type (UFH vs. LMWH); $p=0.334$, OR: $0.425,95 \%$ confidence interval [CI]:
Table 1 Baseline characteristics

\begin{tabular}{|l|l|l|l|}
\hline & $\begin{array}{l}\text { UFH } \\
(\boldsymbol{n}=\mathbf{1 6 1 )}\end{array}$ & $\begin{array}{l}\text { LMWH } \\
(\boldsymbol{n}=\mathbf{1 8 3})\end{array}$ & $p$-Value \\
\hline Age $(\mathrm{y})$ & $66.2 \pm 8.7$ & $64.5 \pm 11.8$ & 0.119 \\
\hline Female & $53(32.9 \%)$ & $60(32.8 \%)$ & 0.979 \\
\hline Hypertension & $67(41.6 \%)$ & $68(37.2 \%)$ & 0.398 \\
\hline Diabetes & $106(65.8 \%)$ & $109(59.6 \%)$ & 0.230 \\
\hline Dyslipidemia & $117(72.6 \%)$ & $144(78.7 \%)$ & 0.193 \\
\hline Current smoker & $79(49.1 \%)$ & $93(50.8 \%)$ & 0.746 \\
\hline eGFR (mL/min) & $54.3 \pm 18.5$ & $58.4 \pm 26.9$ & 0.099 \\
\hline Anterior MI & $86(53.4 \%)$ & $94(51.4 \%)$ & 0.704 \\
\hline NSTEMI & $19(11.8 \%)$ & $24(13.1 \%)$ & 0.713 \\
\hline Cardiogenic shock & $33(20.5 \%)$ & $41(22.4 \%)$ & 0.667 \\
\hline PCI & $134(83.2 \%)$ & $151(82.5 \%)$ & 0.860 \\
\hline IABP duration (h) & $106.1 \pm 76.8$ & $100.3 \pm 47.2$ & \\
\hline IABP duration $\leq 72$ & $77(47.8 \%)$ & $66(36.1 \%)$ & 0.415 \\
\hline IABP duration $>72$ & $84(52.2 \%)$ & $117(63.9 \%)$ & $0.029^{a}$ \\
\hline CRUSADE score & $44.1 \pm 11.0$ & $41.7 \pm 15.5$ & \\
\hline $\begin{array}{l}\text { CRUSADE } \\
\text { score } \leq 40\end{array}$ & $60(37.3 \%)$ & $87(47.5 \%)$ & 0.106 \\
\hline $\begin{array}{l}\text { CRUSADE } \\
\text { score }>40\end{array}$ & $101(62.7 \%)$ & $96(52.5 \%)$ & 0.063 \\
\hline LVEF & $49.0 \pm 13.3$ & $51.2 \pm 14.1$ & 0.138 \\
\hline
\end{tabular}

Abbreviations: AMI, acute myocardial infarction; eGFR, estimated glomerular filtration rate; IABP, intra-aortic balloon counterpulsation; LMWH; low-molecular-weight heparin; LVEF, left ventricular ejection fraction; MI, myocardial infarction; NSTEMI, non-ST segment elevation myocardial infarction; $\mathrm{PCl}$, percutaneous coronary intervention; $\mathrm{UFH}$, unfractionated heparin.

${ }^{\mathrm{a}} \mathrm{p}<0.05$.

Table 2 Complications results according to treatment group during intra-aortic balloon counterpulsation

\begin{tabular}{|l|l|l|l|}
\hline & $\begin{array}{l}\text { UFH } \\
(\boldsymbol{n}=\mathbf{1 6 1 )}\end{array}$ & $\begin{array}{l}\text { LMWH } \\
(\boldsymbol{n}=\mathbf{1 8 3})\end{array}$ & $\begin{array}{l}\boldsymbol{p} \text {-Value } \\
\text { (Chi-square test) }\end{array}$ \\
\hline Ischemia & $5(3.1 \%)$ & $2(1.1 \%)$ & 0.259 \\
\hline Bleeding & $46(28.6 \%)$ & $40(21.9 \%)$ & 0.170 \\
\hline $\begin{array}{l}\text { Major } \\
\text { bleeding }\end{array}$ & $16(9.9 \%)$ & $6(3.3 \%)$ & 0.014 \\
\hline $\begin{array}{l}\text { Death in } \\
\text { hospital }\end{array}$ & $37(23.0 \%)$ & $46(25.1 \%)$ & 0.705 \\
\hline
\end{tabular}

Abbreviations: LMWH, low-molecular-weight heparin; UFH, unfractionated heparin.

0.075-2.415). Ischemia was not statistically associated with IABP duration (OR: 0.636, 95\% CI: 0.110-3.672; $p=0.612$ ) and cardiogenic shock (OR: 0.603, 95\% CI: 0.103-3.532; $p=0.575 ;$ - Table 2).

The Association between Bleeding and Heparin Type As shown in - Tables 3-4, bleeding events (including minor and major) occurred in 46 (28.6\%) patients in the UFH group and $40(21.9 \%)$ patients in the LMWH group. The Chi-square 
Table 3 Logistic regression analysis of potential factors associated with ischemia

\begin{tabular}{|l|l|l|l|}
\hline & $p$-Value & OR & $95 \% \mathrm{Cl}$ \\
\hline Heparin type & 0.334 & 0.425 & $0.075-2.415$ \\
\hline $\begin{array}{l}\text { IABP time } \\
\text { groups } \leq 72 \mathrm{~h} \\
\text { and }>72 \mathrm{~h} \text { ) }\end{array}$ & 0.612 & 0.636 & $0.110-3.672$ \\
\hline Cardiogenic shock & 0.575 & 0.603 & $0.103-3.532$ \\
\hline Diabetes & 0.972 & 1.033 & $0.162-6.579$ \\
\hline Age & 0.605 & 1.025 & $0.934-1.125$ \\
\hline Female & 0.486 & 0.543 & $0.097-3.033$ \\
\hline Hypertension & 0.548 & 1.729 & $0.290-10.286$ \\
\hline
\end{tabular}

Abbreviations: $\mathrm{Cl}$, confidence interval; IABP, intra-aortic balloon counterpulsation; OR, odds ratio.

Table 4 Logistic regression analysis of any bleeding and major bleeding

\begin{tabular}{|l|l|l|}
\hline & Any bleeding & Major bleeding \\
\hline Heparin type & $p=0.292$ & $p=0.020$ \\
& OR: 0.762 & OR: 0.313 \\
& $95 \%$ Cl: $0.460-1.264$ & $95 \%$ Cl: $0.118-0.835$ \\
\hline $\begin{array}{l}\text { Cardiogenic } \\
\text { shock }\end{array}$ & $p=0.115$ & $p=0.087$ \\
& OR: 0.624 & OR: 0.438 \\
& $95 \%$ Cl: $0.346-1.122$ & $95 \%$ Cl: $0.170-1.127$ \\
\hline IABP time & $p=0.005$ & $p=0.364$ \\
(groups $\leq 72 \mathrm{~h}$ & OR: 2.047 & OR: 1.151 \\
and $>72$ h) & $95 \%$ Cl: $1.239-3.383$ & $95 \%$ Cl: $0.620-3.683$ \\
\hline Crusade score & $p=0.804$ & $p=0.670$ \\
(groups $\leq 40$, & OR: 0.936 & OR: 0.812 \\
$>40)$ & $95 \%$ Cl: $0.553-1.583$ & $95 \%$ Cl: $0.310-2.122$ \\
\hline
\end{tabular}

Abbreviations: $\mathrm{Cl}$, confidence interval; IABP, intra-aortic balloon counterpulsation; OR, odds ratio.

test did not reveal the statistical significance between the two groups ( $p=0.170 ;-$ Table 3 ). The logistic regression analysis failed to reveal an association between bleeding and heparin type (OR: 0.762, 95\% CI: 0.460-1.264; $p=0.292$; -Table 4). There was a statistically significant association between bleeding and IABP duration (OR: 2.047, 95\% CI: $1.239-3.383 ; p=0.005)$. Major bleeding events occurred in $16(9.9 \%)$ patients in the UFH group and six (3.3\%) patients in the LWMH group ( - Table 4 ). The Chi-square test revealed a statistically significant difference $(p=0.014 ;-$ Table 3$)$. The use of LMWH was associated with less major bleeding (OR: 0.313, 95\% CI: 0.118-0.835; $p=0.020$; - Table 4).

\section{The Hemoglobin and Platelet Count between Unfractionated Heparin and Low-Molecular-Weight Heparin Groups}

As shown in - Table 5, the hemoglobin level did not differ between the two groups prior to IABP $(130.9 \pm 21.9$ and $131.0 \pm 21.0 \mathrm{~g} / \mathrm{L}$ in the UFH and LMWH groups, respectively). In both groups, the hemoglobin fell after IABP $(113.8 \pm 22.4$ and $115.1 \pm 21.8 \mathrm{~g} / \mathrm{L}$ in the UFH and LMWH groups, respectively). The platelet count did not differ between the two groups prior to $\operatorname{IABP}\left(187.4 \pm 53.0 \times 10^{9} / \mathrm{L}\right.$ vs. $\left.196.3 \pm 40.4 \times 10^{9} / \mathrm{L}\right)$. The platelet count decreased after IABP in both groups $\left(144.6 \pm 62.7 \times 10^{9} / \mathrm{L}\right.$ and $\left.141.5 \pm 58.8 \times 10^{9} / \mathrm{L}\right)$.

\section{Discussion}

The present study involved patients with AMI, who were planned for intra-aortic balloon pump insertion, and compared the clinical complications between the use of LMWH and UFH. Leg ischemia is an important complication during IABP, which rarely induces catastrophic consequences for patients. ${ }^{17}$ In the present study, the rate of ischemia appeared to be lower in patients who received LMWH (1.1 vs. 3.1\% for patients receiving UFH). However, the statistical comparison did not reveal a significant reduction $(p=0.259$; - Table 3 ). The regression analysis also failed to reveal the association of ischemia with heparin type, IABP time, and cardiogenic shock (-Table 2). Arterial thromboembolism was not confirmed with vascular ultrasonography in two of the five patients who developed ischemia after receiving UFH, and both patients developed ischemia after receiving LMWH. The reasons for this discrepancy remains unclear. Furthermore, low blood flow velocity or peripheral vascular disease was not found by ultrasonography. Moreover, the microthrombus, which was a probable cause, was not excluded.

The rate of any bleeding events did not differ between the two groups. The IABP duration was an independent risk factor for all bleeding events. However, the rate of major bleeding events was significantly lower in the LMWH group than in the UFH group ( $p=0.014,-$ Table 4$)$. The principal finding of the multivariate logistic regression analysis revealed that the use of LMWH was associated with less major bleeding (OR: 0.313, 95\% CI: $0.118-0.835 ; p=0.020$ ). This result was different from that of the ATOLL STEMI Treated With Primary Angioplasty and Intravenous Lovenox or Unfractionated Heparin (UFH) (ATOLL) trial. Major bleeding, as the primary composite endpoint, was not significantly reduced by LMWH (enoxaparin, $p=0.79$ ) in the ATOLL trial. However, in the per-protocol analysis of the ATOLL trial, and pertinent to $>87 \%$ of the study population,

Table 5 Hemoglobin and platelet count

\begin{tabular}{|l|l|l|l|l|l|}
\hline & $\begin{array}{l}\text { Hemoglobin prior } \\
\text { to IABP }(\mathbf{g} / \mathbf{L})\end{array}$ & $\begin{array}{l}\text { Hemoglobin trough } \\
\text { during IABP }(\mathbf{g} / \mathbf{L})\end{array}$ & $\begin{array}{l}\text { Platelet prior to } \\
\text { IABP }\left(10^{9} / \mathbf{L}\right)\end{array}$ & $\begin{array}{l}\text { Platelet trough } \\
\text { during IABP }\left(10^{9} / \mathbf{L}\right)\end{array}$ & $p$-Value \\
\hline UFH & $130.9 \pm 21.9$ & $113.8 \pm 22.4$ & $187.4 \pm 53.0$ & $144.6 \pm 62.7$ & $<0.01$ \\
\hline LMWH & $131.0 \pm 21.0$ & $115.1 \pm 21.8$ & $196.3 \pm 40.4$ & $141.5 \pm 58.8$ & $<0.01$ \\
\hline$p$-Value & 0.934 & 0.568 & 0.078 & 0.639 & \\
\hline
\end{tabular}

Abbreviations: IABP, intra-aortic balloon counterpulsation; LMWH, low molecular-weight heparin; UFH, unfractionated heparin. 
enoxaparin reduced the rate of major bleeding (relative risk [RR]: 0.46, 95\% CI: 0.21-1.01, $p=0.050$ ), which significant improved the net clinical benefit (RR: $0.46,95 \% \mathrm{CI}: 0.3-0.74$, $p=0.0002) .{ }^{18}$ A meta-analysis (including 23 trials and representing 30,966 patients) also revealed that enoxaparin is associated with the reduction in the incidence of major bleeding $(0.80,0.68-0.95 ; p=0.009){ }^{19}$ Another meta-analysis that included 10 studies, which comprised of 16,286 patients (with STEMI and received PCI), revealed that $\mathrm{LMWH}$ was associated with the reduction in mortality (RR: $0.51,95 \% \mathrm{CI}: 0.41-0.64$ ) and major bleeding (RR: 0.68, 95\% CI: 0.49-0.94), when compared with UFH, for patients who received PCI for ST-elevated myocardial infarction. ${ }^{20}$ In the present study, the less major bleeding in the LMWH group was not associated with lower mortality. One possible explanation is that patients who frequently needed IABP had shock, heart failure, or hemodynamic instability. Furthermore, the mortality rate of these patients was higher when compared with that for common STEMI patients. Therefore, IABP did not exhibit an improvement in prognosis. Another explanation is that two kinds of LMWH (enoxaparin and nadroparin) were used. However, studies have indicated that there is no difference between these two formulations in terms of bleeding and preventing thromboembolism. More researchers have considered that enoxaparin can benefit STEMI patients with less bleeding, and that nadroparin performs well in preventing venous thromboembolism. ${ }^{21}$ However, no study has determined which effect would be more beneficial for STEMI patients with IABP.

Another difference reported by previous studies is that the CRUSADE score has been generally used to evaluate the bleeding risk of ACS patients, and suggested this to be extended for STEMI patients. $^{22,23}$ In the present study, a high CRUSADE score was not a risk factor of bleeding or major bleeding in AMI patients with IABP. The rate of bleeding in the present study $(28.6 \%$ in the UFH group and $21.9 \%$ in the LMWH group) was also higher when compared with the CRUSADE study. It was considered that the main possible reason was that the use of IABP (a continuous artery intubation device) may increase the bleeding rate. In addition, this is also correlated to the small sample size.

In 1968, IABP was first used to support the circulation of patients with cardiac shock. ${ }^{24}$ IABP simultaneously increases coronary blood flow and decreases myocardial oxygen demand. Thus, this achieves the purpose of ameliorating the ischemia and consequently enhancing the cardiac output. ${ }^{25}$ Regardless of the major success, thrombosis and hemorrhage remains as the major issues. ${ }^{26,27}$ Previous studies have revealed that multiple factors influence the development of these complications in patients who received IABP, including the catheter technique, the size of balloons, the duration of balloon treatment, the age of patients, comorbidity, and the use of antiplatelet/anticoagulant agents. ${ }^{28}$ With the increase in use of $8 \mathrm{~F}$ catheters, the risk of ischemia has been decreasing in patients with IABP. ${ }^{29}$ However, bleeding remains as a significant challenge. Merely few studies (one clinical trial and two cohort studies) have attempted to establish the efficacy and safety of alternative agents to traditional UFH during IABP. ${ }^{30-32}$ The superiority of LMWH to UFH in preventing venous thromboembolism and thrombosis in hemodialysis patients has been established. ${ }^{33}$ It was also confirmed that LMWH, compared with UFH, led to significantly less major bleeding in STEMI patients with IABP in the present study.

Although more researches focused on the Impella and extracorporeal membrane oxygenation (ECMO) in recent years, IABP is the still first choice for the patients with AMI undergoing $\mathrm{PCI}$ or surgery because it is easier to use. A recent study showed that in patients with AMI complicated by cardiogenic shock, IABP and IMPELLA have no significant difference on the prognosis. ${ }^{25}$ ECMO can be a good substitute for pulmonary circulation, but its effect on left ventricular assistance is limited. Some retrospective studies and small size randomized studies also showed that the treatment effect of Impella and ECMO was not significantly better in patients with cardiogenic shock compared with IABP. ${ }^{25,34-37}$ Our current study could also provide reference for the anticoagulation scheme of the IABP combined with ECMO treatment. Our further studies will more focus on the anticoagulation scheme of IABP combined with ECMO, Impella, and other ventricular assist devices.

There were some limitations in the present study. The Ddimer and fibrinogen were not collected to assess the propensity to develop thrombosis. In addition, two LMWH formulations (enoxaparin and nadroparin) were used in the present study. However, no difference was noted between these two formulations in terms of bleeding and preventing thrombelastometry. ${ }^{38-40}$ Due to small sample size, enoxaparin and nadroparin were not individually analyzed.

In summary, results of the present study suggest that LMWH can lower the risk of major bleeding and does not increase the risk of ischemia. Furthermore, the IABP time was statistically significant during bleeding events but was not significant during major bleeding events. LMWH is superior in terms of safety and is equally effective to UFH for patients receiving IABP for AMI. For these patients, further studies with a larger sample size are needed to determine whether LMWH can reduce the mortality and bring more benefits.

\section{Authors' Contributions}

M.C. dedicated to study design. X.G., Y.L., and L.X. supported in collection of data. X.G., H.S., D.Z., and L.W. performed data analysis/interpretation. X.G., M.C., X.Y. cooperated in writing (revising) of the manuscript.

\section{Conflict of Interest}

None declared.

\section{References}

1 Goldberg RJ, Spencer FA, Gore JM, Lessard D, Yarzebski J. Thirtyyear trends (1975 to 2005) in the magnitude of, management of, and hospital death rates associated with cardiogenic shock in patients with acute myocardial infarction: a population-based perspective. Circulation 2009;119(09):1211-1219

2 Hasdai D, Harrington RA, Hochman JS, et al. Platelet glycoprotein IIb/IIla blockade and outcome of cardiogenic shock complicating acute coronary syndromes without persistent ST-segment elevation. J Am Coll Cardiol 2000;36(03):685-692

3 Thiele H, Zeymer U, Neumann F-J, et al; Intraaortic Balloon Pump in cardiogenic shock II (IABP-SHOCK II) trial investigators. Intra-aortic 
balloon counterpulsation in acute myocardial infarction complicated by cardiogenic shock (IABP-SHOCK II): final 12 month results of a randomised, open-label trial. Lancet 2013;382(9905):1638-1645

4 Jacob AS, Steingart RH, Schweger MJ. Heparin elimination following continuous infusion during intra-aortic balloon counterpulsation. Cathet Cardiovasc Diagn 1985;11(04):389-392

5 Harrington RA, Becker RC, Cannon CP, et al. Antithrombotic therapy for non-ST-segment elevation acute coronary syndromes: American College of Chest Physicians Evidence-Based Clinical Practice Guidelines (8th edition). Chest 2008;133(6, Suppl)670S-707S

6 Murphy SA, Gibson CM, Morrow DA, et al. Efficacy and safety of the low-molecular weight heparin enoxaparin compared with unfractionated heparin across the acute coronary syndrome spectrum: a meta-analysis. Eur Heart J 2007;28(17):2077-2086

7 Montalescot G, Zeymer U, Silvain J, et al; ATOLL Investigators. Intravenous enoxaparin or unfractionated heparin in primary percutaneous coronary intervention for ST-elevation myocardial infarction: the international randomised open-label ATOLL trial. Lancet 2011;378(9792):693-703

8 Montalescot G, Ellis SG, de Belder MA, et al; Facilitated INtervention with Enhanced Reperfusion Speed to Stop Events Investigators. Enoxaparin in primary and facilitated percutaneous coronary intervention A formal prospective nonrandomized substudy of the FINESSE trial (Facilitated INtervention with Enhanced Reperfusion Speed to Stop Events). JACC Cardiovasc Interv 2010;3 (02):203-212

9 Palamaner Subash Shantha G, Kumar AA, Sethi M, Khanna RC, Pancholy SB. Efficacy and safety of low molecular weight heparin compared to unfractionated heparin for chronic outpatient hemodialysis in end stage renal disease: systematic review and meta-analysis. PeerJ 2015;3:e835

10 Klejna K, Naumnik B, Koc-Żórawska E, Myśliwiec M. Effect of unfractionated and low-molecular-weight heparin on OPG, sRANKL, and von Willebrand factor concentrations during hemodialysis. Clin Appl Thromb Hemost 2014;20(04):433-441

11 Yan HB, Xiang DC, Liu HM, et al. Chinese experts' consensus: STsegment elevation acute myocardial infarction prehospital thrombolytic therapy. Chinese Journal of the Frontiers of Medical Science 2018;10:6-15(electronic version)

12 Thygesen K, Alpert JS, Jaffe AS, et al; Executive Group on behalf of the Joint European Society of Cardiology (ESC)/American College of Cardiology (ACC)/American Heart Association (AHA)/World Heart Federation (WHF) Task Force for the Universal Definition of Myocardial Infarction. Fourth universal definition of myocardial infarction (2018). J Am Coll Cardiol 2018;72(18):2231-2264

13 Prondzinsky R, Lemm H, Swyter M, et al. Intra-aortic balloon counterpulsation in patients with acute myocardial infarction complicated by cardiogenic shock: the prospective, randomized IABP SHOCK Trial for attenuation of multiorgan dysfunction syndrome. Crit Care Med 2010;38(01):152-160

14 Williams B, Mancia G, Spiering W, et al; ESC Scientific Document Group. 2018 ESC/ESH Guidelines for the management of arterial hypertension. Eur Heart J 2018;39(33):3021-3104

15 Cosentino F, Grant PJ, Aboyans V, et al. ESC Scientific Document Group. 2019 ESC Guidelines on diabetes, pre-diabetes, and cardiovascular diseases developed in collaboration with the EASD. Eur Heart J 2020;41(02):255-323

16 Mach F, Baigent C, Catapano AL, et al; Authors/Task Force Members ESC Committee for Practice Guidelines (CPG) ESC National Cardiac Societies. 2019 ESC/EAS guidelines for the management of dyslipidaemias: Lipid modification to reduce cardiovascular risk. Atherosclerosis 2019;290:140-205

17 Meharwal ZS, Trehan N. Vascular complications of intra-aortic balloon insertion in patients undergoing coronary reavscularization: analysis of 911 cases. Eur J Cardiothorac Surg 2002;21(04): 741-747

18 Collet J-P, Huber K, Cohen M, et al; ATOLL Investigators. A direct comparison of intravenous enoxaparin with unfractionated hep- arin in primary percutaneous coronary intervention (from the ATOLL trial). Am J Cardiol 2013;112(09):1367-1372

19 Silvain J, Beygui F, Barthélémy O, et al. Efficacy and safety of enoxaparin versus unfractionated heparin during percutaneous coronary intervention: systematic review and meta-analysis. BMJ 2012;344:e553

20 Navarese EP, De Luca G, Castriota F, et al. Low-molecular-weight heparins vs. unfractionated heparin in the setting of percutaneous coronary intervention for ST-elevation myocardial infarction: a meta-analysis. J Thromb Haemost 2011;9(10):1902-1915

21 Ageno W, Bosch J, Cucherat M, Eikelboom JW. Nadroparin for the prevention of venous thromboembolism in nonsurgical patients: a systematic review and meta-analysis. J Thromb Thrombolysis 2016;42(01):90-98

22 Subherwal S, Bach RG, Chen AY, et al. Baseline risk of major bleeding in non-ST-segment-elevation myocardial infarction: the CRUSADE (Can Rapid risk stratification of Unstable angina patients Suppress ADverse outcomes with Early implementation of the ACC/AHA Guidelines) Bleeding Score. Circulation 2009;119 (14):2168-2194

23 Kadakia MB, Desai NR, Alexander KP, et al; National Cardiovascular Data Registry. Use of anticoagulant agents and risk of bleeding among patients admitted with myocardial infarction: a report from the NCDR ACTION Registry-GWTG (National Cardiovascular Data Registry Acute Coronary Treatment and Intervention Outcomes Network Registry-Get With the Guidelines). JACC Cardiovasc Interv 2010;3(11):1166-1177

24 Kantrowitz A, Tjønneland S, Freed PS, Phillips SJ, Butner AN, Sherman JL Jr. Initial clinical experience with intraaortic balloon pumping in cardiogenic shock. JAMA 1968;203(02):113-118

25 Ouweneel DM, Eriksen E, Sjauw KD, et al. Percutaneous mechanical circulatory support versus intra-aortic balloon pump in cardiogenic shock after acute myocardial infarction. J Am Coll Cardiol 2017;69(03):278-287

26 Patel MR, Thiele H, Smalling RW, et al. A multicenter, randomized, controlled study of mechanical left ventricular unloading with counterpulsation to reduce infarct size prepercutaneous coronary intervention for acute myocardial infarction: rationale and design of the Counterpulsation Reduces Infarct Size Acute Myocardial Infarction trial. Am Heart J 2011;162(01):47-55.e1

27 Pucher PH, Cummings IG, Shipolini AR, McCormack DJ. Is heparin needed for patients with an intra-aortic balloon pump? Interact Cardiovasc Thorac Surg 2012;15(01):136-139

28 Arafa OE, Pedersen TH, Svennevig JL, Fosse E, Geiran OR. Vascular complications of the intraaortic balloon pump in patients undergoing open heart operations: 15-year experience. Ann Thorac Surg 1999;67(03):645-651

29 Kuki S, Taniguchi K, Masai T, Yoshida K, Yamamoto K, Matsuda H. Usefulness of the low profile "True 8" intra-aortic balloon pumping catheter for preventing limb lschemia. ASAIO J 2001;47(06): 611-614

30 Jiang CY, Zhao LL, Wang JA, Mohammod B. Anticoagulation therapy in intra-aortic balloon counterpulsation: does IABP really need anti-coagulation? J Zhejiang Univ Sci 2003;4(05): 607-611

31 Laish-Farkash A, Hod H, Matetzky S, Guetta V. Safety of intraaortic balloon pump using glycoprotein IIb/IIIa antagonists. Clin Cardiol 2009;32(02):99-103

32 Cooper HA, Thompson E, Panza JA. The role of heparin anticoagulation during intra-aortic balloon counterpulsation in the coronary care unit. Acute Card Care 2008;10(04):214-220

33 Lim W, Cook DJ, Crowther MA. Safety and efficacy of low molecular weight heparins for hemodialysis in patients with end-stage renal failure: a meta-analysis of randomized trials. J Am Soc Nephrol 2004;15(12):3192-3206

34 Zeymer U, Bueno H, Granger CB, et al. Acute Cardiovascular Care Association position statement for the diagnosis and treatment of patients with acute myocardial infarction complicated by 
cardiogenic shock: a document of the Acute Cardiovascular Care Association of the European Society of Cardiology. Eur Heart J Acute Cardiovasc Care 2020;9(02):183-197

35 Schrage B, Ibrahim K, Loehn T, et al. Impella support for acute myocardial infarction complicated by cardiogenic shock. Circulation 2019;139(10):1249-1258

36 Schiller P, Hellgren L, Vikholm P. Survival after refractory cardiogenic shock is comparable in patients with Impella and venoarterial extracorporeal membrane oxygenation when adjusted for SAVE score. Eur Heart J Acute Cardiovasc Care 2019;8(04): 329-337

37 Wernly B, Seelmaier C, Leistner D, et al. Mechanical circulatory support with Impella versus intra-aortic balloon pump or medical treatment in cardiogenic shock-a critical appraisal of current data. Clin Res Cardiol 2019;108(11):1249-1257

38 Vlasin M, Dvorak M, Dvorakova M, Rauser P, Lexmaulova L, Gregor Z. Direct comparison of enoxaparin and nadroparin in a rabbit model of arterial thrombosis prevention. Thromb Res 2010;126(01):56-60

39 Cvirn G, Hoerl G, Tafeit E, et al. Effects of nadroparin, enoxaparin, and unfractionated heparin on endogenous formation of factor Xa and Ila and on thrombelastometry profiles in cord versus adult blood. Neonatology 2011;100(01):23-31

40 Naumnik B, Rydzewska-Rosołowska A, Myśliwiec M. Different effects of enoxaparin, nadroparin, and dalteparin on plasma TFPI during hemodialysis: a prospective crossover randomized study. Clin Appl Thromb Hemost 2011;17(05):480-486 